sample quoted, it is obvious that the patients tested had a longstanding illness, and that lithium had substantially reduced their relapses. This, by itself, is a sign that they were good compliance subjects, and brings into question the generalisability of the findings to poorly compliant patients: in particular that lithium leads to better compliance and therefore fewer relapses.

Secondly, as regards the method, it seems that the authors did not control for input of time. The education group had an educational-video presentation while the control group had nothing. This weakens the results of the study further, as it could be argued that any video presentation on a subject of mental health could have an effect on the patients' attitudes in itself.

We would like to draw attention to the fact that, while using the lithium knowledge test (LKT) repeatedly during this study, no account seems to have been taken of practice effect. I would have been interested to have seen the questionnaires themselves as well as their reliability and validation data.

Finally, we felt it would be of great use to see if the long-term effects of the study improved compliance and safety, and reduced relapse. This would require a longer follow-up than the 24 weeks of this study.

Athanasios DOUZENIS

NEIL BRENER

Charing Cross Hospital

Fulham Palace Road

London W6 8RF

Authors' RePLy: We thank Drs Douzenis \& Brener for their interest in our work, concerning which they raise a number of points of method and interpretation.

The primary finding of our study was that the lithium information package led to a substantial improvement in patient knowledge about their treatment, which was sustained over 24 week follow-up. It is difficult to understand what Drs Douzenis \& Brener mean by their statement that our study took no account of practice effects with the lithium knowledge test (LKT), when a control group was used to take such effects into account.

With regard to the effect of the educational programme on attitudes towards lithium, we state quite clearly in our article that improved attitude was not mainly due to the information programme, but that other factors in the study probably contributed. The point we make is simply that attitude to lithium was not harmed by a research programme in which information was presented about its adverse effects and, in fact, there was a modest improvement in attitude.
The patients attending our lithium clinic were all at different stages of treatment, not always of prolonged duration. In our experience, the mix of patients is typical of that found in lithium clinics elsewhere in the country. It is, therefore, likely that our findings are generalisable to other lithium clinic populations. We plan, with the help of sponsorship, to make the full educational programme widely available so that others can see for themselves.

The patients were not selected by us as 'good compliance' subjects, and we have examined selfselection in the two years up to the study. Eighteen patients left the clinic in that time. They were of comparable age and sex, and the mean durations of their illnesses and remissions were similar to those for patients still attending. Their reasons for leaving appear to relate to social mobility, physical illness or old age. Those remaining, on entering the education programme, showed attitudes on the lithium attitudes questionnaire (LAQ) suggesting doubtful compliance. As many as $45 \%$ expressed opposition to continuing with their lithium treatment.

Finally, the question of whether compliance would be improved, and relapse rate reduced, over the long term, as a result of proper education, remains to be answered. Our study was not designed to address this issue. Unfortunately, it would not be possible to perform such a study using a parallel control group, because of the ethical problems of purposely leaving a large group of patients relatively uninformed about their treatment. In our own case, long-term followup of patients has been handicapped by the dispersal of patients from the Lithium Clinic, due to the introduction of sector-related services in Sheffield.

Norman S. HARVEY

Malcolm Peet

University of Sheffield Department of Psychiatry

Royal Hallamshire Hospital

Glossop Road

Sheffield S10 2JF

\section{Computerised tomography in schizophrenia}

SIR: Thank you for asking me to reply to Dr Miller's letter (Journal, June 1991, 158, 863). "Unnecessarily dogmatic" I happily accept: "probably wrong" I think is unlikely. Nonetheless, Dr Miller raises an important issue. The realisation that the minor structural brain abnormalities seen in some schizophrenic patients might be non-progressive has been important in the conceptual shift from schizophrenia being a neurodegenerative disorder, to a neurodevelopmental view. To my eyes, the weight of evidence does not allow us to reject the null hypothesis that there is no progressive enlargement of 
cerebral ventricles in schizophrenia. As Dr Miller states, one or two studies have reported a weak correlation. By the same token, at least one study has reported an inverse correlation: that lateral ventricles somehow shrink as the illness progresses.

Overall, this pattern of findings suggests an occasional Type 1 statistical error, hardly surprising given the large number of studies now in existence and the many possible confounding factors. Even if Dr Miller were correct, it is still a big jump to suggest that progressive brain changes might be arrested by antipsychotic drug treatment. It would be equally reasonable to say that prolonged drug treatment were the cause. In any case, conscientious clinicians who already pay close attention to drug treatment will continue to do so, whichever view turns out to be right.

Academic Department of Psychiatry

SHÔN LEWIS Charing Cross and Westminster Medical School London W6 8RP

\section{'The disease concept of alcoholism'}

SIR: Professor Griffith Edwards has kindly commented on my review of Jellinek's monograph, The Disease Concept of Alcoholism (Journal, March 1991, 158, 431). Like him I have been unable to find any information that is not generally known about $\mathrm{Dr}$ E. M. Jellinek. As far as I am aware, after making enquiries, no biography of Jellinek has ever been written, although my understanding is that one is currently being undertaken in the USA. Mr Archer Tongue, a former Director of the International Council on Alcohol and Addictions, who has more knowledge of workers in the alcoholism field than most, was also unable to provide any further information.

It is interesting that Professor Edwards states that Jellinek's ideas really have to be seen as part of a continuing process, with which I would agree, although I myself am not familiar with the references he cites; but there is no doubt, as outlined in the excellent review by Levine (1978) that such concepts as "The disease concept of alcoholism", extended, particularly in the United States, throughout the 19th and 20th centuries, as has the continued debate as to whether alcoholism is best regarded as an illness or as deviant behaviour.

The comment that the alcohol dependence syndrome is a more socially acceptable form of the disease concept is not my original statement but the view of Heather \& Robertson (1981) who state ... "therefore the alcohol dependence syndrome is a conception of abnormal drinking based primarily on psychobiological dependence with impaired control as its leading symptom. With the substitution of loss of control for impaired control, how different is this from Jellinek's (1960) formulation?"

Despite this criticism, the alcohol dependence syndrome offers those of us working in this field a practical definition, linking alcohol dependence to drug dependence, and also giving us a model in which the dependence phenomenon is not all or none, but graded, a concept which has considerable importance, both in treatment goals and research into different populations varying in their level of dependence.

HeAther, N. \& Robertson, I. (1981) Controlled Drinking. London: Methuen.

LEVINE, H. G. (1978) The discovery of addiction, changing conceptions of habitual drinkers in America. Journal of Studies of Alcohol, 39, 143-174.

Withington Hospital

West Didsbury

Manchester M20 8LR

Brian Hore

\section{Double blind acceptance}

SIR: I am certainly happy to accept that my position and that of Double (Journal, April 1991, 158, 573574) do not now differ materially. He is right to point out that blindness is prone to be used as a buzz word emptied of its legitimate meaning, so that one should be happier about a study in which the investigators accept they cannot achieve blinding, than one in which blindness is claimed, but is illusory. (In the same way, the key concept of random allocation becomes vacuous when 'random' is taken to mean 'arbitrary' and no longer implies specific measures to minimise the possibility of bias being introduced by the admitting clinician.) The application of a method that will be as scientifically valid as possible in a real clinical situation, with the limitations which that inevitably introduces, remains the goal of study design. Scientific rigour in anywhere near an absolute sense is rarely attainable, and the editorial peer review process should regard a study report in which the limitations of the results are specified clearly as more acceptable than one in which the problems have been swept under the carpet, although inferable by a reasonable measure of experience-based lateral thinking.

The application to clinical and preventive practice, in the absence of clearcut results, is also a very important issue. Often one cannot simply ignore an issue: to do so is effectively to act as if the status quo were established. This applies whether the problem 